Elsevier Editorial System(tm) for Toxicon Manuscript Draft

Manuscript Number: TOXCON-D-17-00413R1

Title: The travel diaries of tetanus and botulinum neurotoxins

Article Type: SI:Botulinum \& other toxins

Keywords: Axonal retrograde transport; botulinum neurotoxin; tetanus toxin; clostridial neurotoxin; endocytosis, neuromuscular junction.

Corresponding Author: Professor Giampietro Schiavo,

Corresponding Author's Institution: University College London

First Author: Sunaina Surana

Order of Authors: Sunaina Surana; Andrew P Tosolini; Ione F Meyer; Alexander D Fellows; Sergey S Novoselov; Giampietro Schiavo

Abstract: Tetanus (TeNT) and botulinum (BoNT) neurotoxins, the causative agents of tetanus and botulism, respectively, are the most potent toxic molecules known to mankind. This extreme potency is attributed to: i) their specificity for essential components of the neurotransmitter release machinery present at vertebrate synapses, and ii) their highaffinity targeting to motor neurons by binding to polysialogangliosides and protein receptors. Comprising the clostridial neurotoxin family, TeNT and BoNTs engage distinct surface receptors and intracellular sorting pathways in neurons. BoNTs bind to the intraluminal domain of specific synaptic vesicle proteins that are exposed to the extracellular milieu upon exocytosis, and are taken up by synaptic vesicle recycling. A sizeable proportion of BoNT molecules remain at the neuromuscular junction, where their protease moiety is released into the cytoplasm, blocking synaptic transmission and causing flaccid paralysis. In contrast, TeNT undergoes binding to specific components of the basal membrane at the neuromuscular junction, is endocytosed into motor neurons and sorted to axonal signalling endosomes. Following this, TeNT is transported to the soma of motor neurons located in the spinal cord or brainstem, and then transcytosed to inhibitory interneurons, where it blocks synaptic transmission. TeNT-induced impairment of inhibitory input leads to hyperactivity of motor neurons, causing spastic paralysis, which is the hallmark of tetanus. This review examines the molecular mechanisms leading to the entry, sorting and intracellular trafficking of TeNT and BoNTs. 


\section{The travel diaries of tetanus and botulinum neurotoxins}

2 Sunaina Surana ${ }^{1, \star}$, Andrew P. Tosolini ${ }^{1, \star}$, Ione F. G. Meyer ${ }^{1,2}$, Alexander D. Fellows ${ }^{1}$,

3 Sergey S. Novoselov ${ }^{1}$ and Giampietro Schiavo ${ }^{1,3,4 \ddagger}$

4

5 'Sobell Department of Motor Neuroscience \& Movement Disorders, UCL Institute of 6 Neurology, University College London, London WC1N 3BG, UK

$7 \quad{ }^{2} \mathrm{MRC}$ Centre for Neuromuscular Diseases, National Hospital for Neurology and

8 Neurosurgery, Queen Square, London WC1N 3BG, UK

$9{ }^{3}$ Discoveries Centre for Regenerative and Precision Medicine, University College London

10 Campus, London WC1N 3BG, UK

$11{ }^{4}$ UK Dementia Research Institute at UCL, London WC1E 6BT, UK

12

$13{ }^{*}$ These authors have contributed equally to this work

$15{ }^{\ddagger}$ Corresponding author: Professor Giampietro Schiavo FMedSci FRSB, Sobell Department of 16 Motor Neuroscience \& Movement Disorders, UCL Institute of Neurology, University College 17 London, London WC1N 3BG, UK. Phone: 00447918738393. e-mail: 18 giampietro.schiavo@ucl.ac.uk

Running title: Clostridial neurotoxin uptake and transport

Words (with references): 10,958

Characters (with spaces): 74,905

Keywords: Axonal retrograde transport, botulinum neurotoxin, tetanus toxin, clostridial neurotoxin, endocytosis, neuromuscular junction. 
30 Tetanus (TeNT) and botulinum (BoNT) neurotoxins, the causative agents of tetanus and botulism, respectively, are the most potent toxic molecules known to mankind. This extreme potency is attributed to: i) their specificity for essential components of the neurotransmitter release machinery present at vertebrate synapses, and ii) their high-affinity targeting to motor neurons by binding to polysialogangliosides and protein receptors. Comprising the clostridial neurotoxin family, TeNT and BoNTs engage distinct surface receptors and intracellular sorting pathways in neurons. BoNTs bind to the intraluminal domain of specific synaptic vesicle proteins that are exposed to the extracellular milieu upon exocytosis, and are taken up by synaptic vesicle recycling. A sizeable proportion of BoNT molecules remain at the neuromuscular junction, where their protease moiety is released into the cytoplasm, blocking synaptic transmission and causing flaccid paralysis. In contrast, TeNT undergoes binding to specific components of the basal membrane at the neuromuscular junction, is endocytosed into motor neurons and sorted to axonal signalling endosomes. Following this, TeNT is transported to the soma of motor neurons located in the spinal cord or brainstem, and then transcytosed to inhibitory interneurons, where it blocks synaptic transmission. TeNT-induced impairment of inhibitory input leads to hyperactivity of motor neurons, causing spastic paralysis, which is the hallmark of tetanus. This review examines the molecular mechanisms leading to the entry, sorting and intracellular trafficking of TeNT and BoNTs.

Highlights

- Tetanus and botulinum neurotoxins undergo long range traffic in mammalian neurons

- Signalling endosomes and autophagomes mediate the transport of these neurotoxins

- The binding of tetanus toxin to the basal membrane is key for its uptake in neurons

\section{Historical background}

Tetanus (TeNT) and botulinum (BoNT) neurotoxins have been studied intensely over the last century, while BoNTs have attracted worldwide attention in the last 25 years for their everincreasing medical applications. These neurotoxins are produced by Clostridium tetani and various serotypes of Clostridium botulinum, which together form the clostridial neurotoxin (CNT) family. The unmistakable clinical symptoms of tetanus toxicity were first reported in Egyptian and Indian documents before 1500 BC. It was Hippocrates (460-370 BC) who coined the term твтаvoo (translated to 'tension' in Ancient Greek) to describe these symptoms when studying the progressive spastic paralysis developed by a sailor as a consequence of an injury caused while handling the anchor of his boat (Udwadia, 1994). 
64 However, the aetiology of tetanus remained a mystery until the end of the $19^{\text {th }}$ century, when 65 the efforts of Carle and Rattone in Turin, Nicolaier in Göttingen and Kitasato in Berlin led to 66 the conclusion that tetanus was a transmissible disease caused by an anaerobic sporigenic bacterium present in the soil (Udwadia, 1994). Although Nicolaier was able to report the presence of a strychnine-like substance in the supernatant of these bacterial cultures, it was Faber in 1890 who isolated TeNT and demonstrated its physiological role as the causative agent of the spastic paralysis observed during tetanus (Udwadia, 1994). Importantly, the availability of methods to isolate TeNT subsequently allowed Marie in 1897, and Meyer, Ranson and others thereafter to demonstrate that TeNT was able to reach the central nervous system (CNS), mediating its central affects after travelling along peripheral motor nerves (Habermann, 1989; Marie, 1897; Udwadia, 1994). These findings, thus, set the stage for the modern analyses of CNT trafficking in neurons.

Botulism, characterised by a general muscle weakness, was described independently in the same period as TeNT by Kerner (1822), followed by the isolation of $C$. botulinum and the first serotype of BoNT by van Ermengem in 1895 (van Ermengem, 1979). Traditionally seven BoNT serotypes have been described in the literature including BoNT/A, BoNT/B, BoNT/C, BoNT/ D, BoNT/E, BoNT/F, and BoNT/G (Montal, 2010; Poulain et al., 2015; Pirazzini et al., 2017). However, most recently, an eighth BoNT serotype has been discovered and named BoNT/X (Zhang et al., 2017). Each individual serotype contains multiple subtypes of toxins (e.g., BoNT/A1, BoNT/A2, etc.) (Poulain et al., 2015) with unique activities, synaptic targets and downstream intracellular signalling (Pirazzini et al., 2017).

These discoveries, together with the isolation of different $C$. botulinum toxigenic strains and studies on their intracellular activity and synaptic targets of TeNT and BoNTs in the 1990s (Montal, 2010; Pirazzini et al., 2017), have revealed important insights into a complex protein machinery responsible for the neuronal targeting, uptake and inhibition of synaptic transmission by these neurotoxins. As a consequence, the study of the mode of action of TeNT and BoNTs continue to have direct impact on several disciplines, including microbiology, pharmacology, physiology, cell biology, biochemistry and molecular medicine. TeNT and BoNTs have been used as tools of discovery in bioscience to dissect the mechanisms of regulated secretion and intracellular trafficking, and as CNS-targeting molecules for DNA vaccines and therapeutics (Behzadi et al., 2016; Toivonen et al., 2010). The need for further in-depth characterisation of the mechanism of action of these neurotoxins both in vitro and in vivo is further highlighted by the widespread use of BoNTs to treat pathologies beyond the classical area of synaptic hyperactivity, such as chronic migraine, depression and aesthetic/dermatological applications (Pirazzini et al., 2017). In 
100 many newborns affected by tetanus neonatorum

101 (http://apps.who.int/gho/data/view.main.1520 46) making the development of efficient

102 countermeasures an urgent priority.

\section{Mechanism of Action}

105

106

107

108

109

110

111

112

113

114

115

116

117

118

119

120

121

122

123

124

125

126

127

128

129

130

131

132

133

134

TeNT displays lethal dose, $50 \%\left(\mathrm{LD}_{50}\right)$ ranging between 0.1 and $5 \mathrm{ng} / \mathrm{kg}$ of body weight in mice (Gill, 1982), while the BoNT LD 50 lies between 0.1 and $500 \mathrm{ng} / \mathrm{kg}$ (Pirazzini et al., 2017). The $\mathrm{LD}_{50}$ for both neurotoxins, however, can greatly vary in different species (Gill, 1982). There are many factors that determine the precise time of symptom onset (i.e., paralysis) after CNT intoxication, including dose, route of application and species. For TeNT, the incubation period between the initial injury and the onset of clinical symptoms is highly variable (from 1-2 days to a couple of months) (Udwadia, 1994) and includes the time needed for the spores to germinate into vegetative bacteria, which, after autolysis, presumably release the neurotoxin into the bloodstream. Shorter incubation periods are usually associated with TeNT of higher severity, in which the symptoms reach their peak in 7-10 days, plateau for 1-2 weeks and gradually decline in additional 1-2 weeks, although muscle stiffness may persists for weeks or even months after recovery (Udwadia, 1994). BoNTs, on the other hand, are typically released into the body via food contaminated by spores, in which the storage conditions allowed their germination and the expression of the progenitor toxin complex formed by BoNTs and non-toxic neurotoxin-associated proteins (NAPs). NAPs comprise a non-toxic non-haemagglutinin component (NTNHA) that plays an important role in protecting BoNTs from the harsh gastrointestinal tract, and other subunits that enable binding to the surface of intestinal cells for subsequent transcytosis of the neurotoxic complex from the apical membrane to the basolateral membrane of intestinal epithelium (Amatsu et al., 2013; Gu et al., 2012; Lee et al., 2013; Lee et al., 2014; Sugawara et al., 2014; Yao et al., 2014). Once released, the BoNT progenitor complex sequesters Ecadherin in its monomeric form, blocking E-cadherin dimer formation, thus weakening the trans-epithelial barrier (Lee et al., 2014; Sugawara et al., 2014). This process leads to bulk entry of neurotoxin into the bloodstream and can accelerate intoxication.

After entering the general circulation, TeNT and BoNTs bind with high affinity to the presynaptic membrane of the motor neuron at the neuromuscular junction (NMJ) where they are rapidly internalised (Montal, 2010; Rummel, 2016) (Figure 1A). BoNTs mainly remain at the NMJ and inhibit the release of the excitatory neurotransmitter acetylcholine (Figure 1), blocking muscle excitation-contraction coupling and thus causing a flaccid paralysis. In contrast, TeNT enters motor neuron axon terminals through endocytosis at the NMJ (Figure 
135 1B) and is predominantly retrogradely transported in axonal signalling endosomes to the 136 soma of motor neurons in the spinal cord (Schmieg et al., 2014) (Figure 1C). TeNT is 137 subsequently transcytosed into inhibitory interneurons where it blocks neuroexocytosis 138 through the cleavage of the SNARE VAMP/synaptobrevin, thus inhibiting neurotransmitter 139 release from intoxicated interneurons to motor neurons (Figure 1D). As a consequence, the 140 balance between excitatory and inhibitory inputs to motor neurons is disrupted, eliciting 141 hyperactive motor neurons and spasticity. In addition to inhibitory interneurons (i.e., 142 glycinergic and GABAergic), excitatory interneurons (i.e., glutamatergic and cholinergic) also 143 respond to TeNT application but with different sensitivity and effects (Bergey et al. 1987; 144 McMahon et al., 1992; Williamson et al. 1992; Shin et al., 2012). This preference for 145 inhibitory versus excitatory synapses is maintained when TeNT is applied directly into the 146 CNS and underlie the neurodegenerative and epileptogenic effects of TeNT (Bagetta et al., 147 1990; Bowery et al., 1992; Ferecsko et al., 2015), which may result from unopposed release 148 of glutamate from excitatory central synapses.

149 Paradoxically, despite TeNT and BoNTs exert opposing influences on skeletal muscle (i.e., 150 spasticity versus flaccidity), their modes of action are quite similar. Indeed, both CNT family 151 members block neurotransmitter release via specific cleavage of soluble NSF-attachment 152 protein receptor (SNARE) proteins involved in neuroexocytosis (Montecucco et al., 2005). 153 The differences in clinical symptoms arise from preferential site of action in different neurons 154 (Montal, 2010; Rummel, 2016) (Figure 1).

155 Interestingly, the hallmarks of TeNT and BoNT have also been observed in neurons other 156 than motor neurons, including cortical, sensory and sympathetic neurons (Blum et al., 2014; 157 Cordero-Erausquin et al., 2009).

\section{3. Multi-domain structure and function}

160 TeNT and BoNTs are remarkably similar in sequence and structure (Montal, 2010). The 150 $161 \mathrm{kDa}$ single-chain proteins are cleaved by proteases producing an active neurotoxin 162 comprising two chains of $100 \mathrm{kDa}$ (heavy or $\mathrm{H}$ chain) and $50 \mathrm{kDa}$ (light or $\mathrm{L}$ chain), which 163 remain associated via non-covalent interactions and a conserved inter-chain disulphide bond 164 essential for neurotoxicity (de Paiva et al., 1993; Pirazzini et al., 2014; Schiavo et al., 1990).

165 The heavy chain is further subdivided into two $50 \mathrm{kDa}$ domains: the amino terminal $\left(\mathrm{H}_{\mathrm{N}}\right)$ and 166 carboxy terminal $\left(\mathrm{H}_{\mathrm{C}}\right)$ domains (Montal, 2010). X-ray crystallography of BoNT/A (Garcia167 Rodriguez et al., 2007; Lacy et al., 1998; Stevens et al., 1991), BoNT/B (Swaminathan and 168 Eswaramoorthy, 2000), BoNT/E (Kumaran et al., 2009) and TeNT (Masuyer et al., 2017) was 169 used to confirm the spatial orientation of these domains relative to each other. TeNT and 
BoNT/E assume a more compact/closed arrangement, with the $\mathrm{H}_{\mathrm{C}}$ domain interacting closely

171 with the $L$ chain and $H_{N}$, although distinct interaction surfaces are employed by the two CNTs

172 (Kumaran et al., 2009; Masuyer et al., 2017). Conversely, BoNT/A and BoNT/B display an

173 elongated arrangement of the three domains, which are largely separated, with the exception

174 of an extended loop in the amino-terminus of the $\mathrm{H}$ chain (termed belt), which is wrapped

175 around the $L$ chain.

176 The $\mathrm{H}_{\mathrm{C}}$ domain of CNTs is responsible for their neuron-specific binding and is composed of 177 two sub-domains of roughly the same size (Pirazzini et al., 2017). While the amino-terminal 178 sub-domain $\left(\mathrm{H}_{\mathrm{CN}}\right)$ is structurally similar to the carbohydrate-binding domain of the lectin 179 family, the carboxy-terminal sub-domain $\left(\mathrm{H}_{\mathrm{CC}}\right)$ is homologous to domains involved in protein180 protein interactions (Montal, 2010; Pirazzini et al., 2017). It is in the $\mathrm{H}_{\mathrm{Cc}}$ loops of CNTs where 181 the highest degree of sequence and structural divergence lies (Lacy and Stevens, 1999), 182 which ultimately contributes to binding specificity. Crucially, in BoNT/A and BoNT/E, the $\mathrm{H}_{C}$ 183 domain is isolated from the remaining part of the molecule, allowing full access of all surface 184 loops for binding. The close conformation found in BoNT/E and TeNT may instead impose 185 some steric constraints to the full accessibility of $\mathrm{H}_{\mathrm{C}}$ to protein and lipid receptors (Kumaran 186 et al., 2009; Masuyer et al., 2017). Moreover, other portions of TeNT may contribute to 187 enhanced clearance from the NMJ and wider spreading into spinal cord neurons (Ovsepian 188 et al., 2015).

189 The $\mathrm{H}_{\mathrm{C}}$ domains of CNTs bind to polysialogangliosides on the plasma membrane, in 190 particular to G1b gangliosides, with high specificity and affinity (Montecucco, 1986), although 191 binding to other gangliosides series has been reported (e.g. BoNT/A interacts with GQ1b and 192 GT1b, but also to GD1a, albeit with lower affinity) (Kitamura et al., 1980; Takamizawa et al., 193 1986). Binding to polysialogangliosides is facilitated by oligosaccharide-binding sites (one 194 and two, in BoNTs and TeNT, respectively) in the $\mathrm{H}_{\mathrm{CC}}$ sub-domain of the heavy chain 195 (Rummel, 2016; Rummel et al., 2003). Mutations in the carbohydrate binding domain 196 abrogate binding of these toxins to neuronal plasma membranes, thus highlighting the 197 importance of this interaction (Rummel, 2016). Addition of the polysialoganglioside GT1b to 198 NMJs protects the neuron from the toxic effects of BoNT via competitive inhibition and 199 partially abolishes the retrograde transport of TeNT (Stoeckel et al., 1977). In addition, 200 removal of sialic acid residues from the plasma membrane by neuraminidase treatment 201 (Bigalke et al., 1986) or blocking ganglioside biosynthesis (Kitamura et al., 2005; Rummel, 202 2013; Williamson et al., 1999) inhibits CNT activity. Despite the strong requirement of surface 203 polygangliosides for uptake of CNTs, it is clear that they are not unique determinants of 204 binding since TeNT and BoNTs do not compete with each other for internalisation at the 205 NMJ. Additional protein receptor(s) have therefore been suggested to act in conjunction with 
gangliosides, referred to as the dual receptor hypothesis (Montecucco, 1986; Rummel, 2016;

207 Rummel et al., 2007). According to this hypothesis, polysialogangliosides act in one of two 208 ways: i) recruit TeNT and BoNTs to specific regions of the plasma membrane, which are 209 locally enriched in a certain protein receptor, or ii) maintain a specific conformational state of 210 these toxins so as to enable the receptor to bind. In line with this hypothesis, specific protein 211 co-receptors have been identified for most CNTs (see section 4).

212 The $\mathrm{pH}$-dependent translocation of the L-chain from the endocytic lumen into the cytosol is 213 mediated by the amino-terminal part of the $\mathrm{H}$ chain $\left(\mathrm{H}_{N}\right) \cdot \mathrm{H}_{N}$ is composed of a belt closely 214 interacting with the $L$ chain and a central portion containing two very long $\alpha$-helices (Montal, 215 2010; Pirazzini et al., 2016). Although the function of this domain in membrane insertion was 216 first described in the 1980s, the exact mechanism underlying the transfer of the $L$ chain to 217 the cytosol remains, at least in part, controversial (Montal, 2010; Pirazzini et al., 2016). 218 Recent findings have demonstrated that the reduction of the disulphide bridge linking the $\mathrm{H}$ 219 and $L$ chains by the thioredoxin reductase-thioredoxin (TrxR-Trx) system is required for the release of the $L$ chain into the cytosol, and inhibition of TrxR-Trx activity prevents the intoxication of neurons both in vitro and in vivo (Pirazzini et al., 2015; Pirazzini et al., 2014;

222 Zanetti et al., 2015). Reduction of the interchain disulphide bridge is strictly coupled to $L$ 223 chain refolding, since the inhibition of cytosolic chaperone Hsp90 reduces the intracellular 224 activity of BoNTs (Azarnia Tehran et al., 2017). Interestingly, Hsp90 and TrxR-Trx physically 225 interact on the surface of SVs, where they orchestrate a chaperone-redox complex likely to 226 be involved in synaptic protein refolding, which is exploited by the $L$ chains of CNTs to enter 227 the cytosol (Azarnia Tehran et al., 2017).

228 The $\mathrm{L}$ chain contains the catalytic zinc atom and is responsible for the intracellular 229 endopeptidase activity of CNTs, which is directed towards the SNARE proteins $230 \mathrm{VAMP} /$ synaptobrevin 1-3 (BoNT/B, BoNT/D, BoNT/F, BoNT/G, BoNT/HA and BoNT/X, 231 TeNT), SNAP25 (BoNT/A, BoNT/C and BoNT/E) and syntaxin-1 (Montal, 2010; Pirazzini et 232 al., 2016; Zhang et al., 2017). BoNT/X also cleaves the non-canonical substrates VAMP4, 233 VAMP5 and Ykt6 (Zhang et al., 2017). The number of zinc atoms that bind to the $L$ chain 234 varies among different CNTs; while the $L$ chains of TeNT, BoNT/A, BoNT/B and BoNT/F 235 chelate one atom of zinc (Schiavo et al., 1992a; Schiavo et al., 1992b; Schiavo et al., 1993), 236 BoNT/C binds two atoms of zinc with different affinities (Breidenbach and Brunger, 2005; 237 Garcia-Rodriguez et al., 2007; Schiavo et al., 1995). The protease activity of the $L$ chain can 238 be abolished by heavy metal chelators, such as ortho-phenantroline, thus generating inactive 239 apo-neurotoxins (Bhattacharyya and Sugiyama, 1989; Schiavo et al., 1992a). The zinc atom 240 is chelated by two histidines located in the endopeptidase motif (His-Glu-x-x-His); the 241 glutamic acid residue in this motif binds the water molecule necessary for the catalysis (third 
242 ligand), with another glutamic acid (Glu261 in BoNT/A) acts as the fourth ligand (Montal, 243 2010; Pirazzini et al., 2016).

\section{Neuron-specific binding}

246 CNTs are exquisitely neuron-specific and able to bind neurons in vivo at concentrations in the sub-nanomolar regime (Simpson, 2000). Both BoNTs and TeNT interact with the peripheral cholinergic nerve terminals, while TeNT also binds to sympathetic and adrenergic nerve fibres (Rossetto et al., 2001). The $\mathrm{H}_{\mathrm{C}}$ domains are largely responsible for this highaffinity binding, since paralysis caused by native toxins can be counteracted by recombinant $\mathrm{H}_{\mathrm{C}}$ proteins (Lalli et al., 1999; Rummel et al., 2009). Additional targeting information, however, may be encoded elsewhere in the full length neurotoxin (Ovsepian et al., 2015). The neuron-specificity of CNTs is also likely to reflect the complexity of their cellular receptors, which are most probably composed of multiple lipid and protein components forming arrays of presynaptic receptors (APRs) (Montecucco et al., 2004).

256 Polysialogangliosides play a key role in the binding and internalisation of CNTs at the presynaptic membrane, presumably due to their high concentration at the NMJ and their lateral mobility. Interaction of the toxin with polysialogangliosides allows its subsequent interaction with other molecules in the APRs, thus leading to virtually irreversible binding. In addition to polysialogangliosides, APRs contain lipids such as cholesterol and sphingomyelin, GPI-anchored protein(s) and other membrane-bound protein(s) (Montecucco et al., 2004). Interestingly, both TeNT and BoNT/A have been found to bind sphingomyelinenriched membrane microdomains (Herreros et al., 2001; Muraro et al., 2009); additionally, BoNT/A and BoNT/C interact with phosphoinositol lipids (Muraro et al., 2009; Tsukamoto et al., 2005; Zhang and Varnum, 2012). Since BoNTs and TeNT have been proposed to bind distinct co-receptors, the APRs recognised by BoNTs would direct them inside vesicles that are acidified within the NMJ, such as recycling synaptic vesicles (SVs), whereas the APRs binding to TeNT would sort this neurotoxin into signalling endosomes undergoing axonal retrograde transport towards the neuronal soma (Schmieg et al., 2014).

270 Several lines of evidence indicate that BoNTs enter the NMJ by exploiting the process of SV 271 recycling (Montal, 2010; Pirazzini et al., 2017). Accordingly, many CNTs bind to the intraluminal domain of SV proteins, which are exposed to the extracellular milieu upon SV

273 exocytosis (Figure 1B). BoNT/B, BoNT/D, BoNT/C and BoNT/G interact with the calcium274 sensing proteins synaptotagmin-1 and/or -2 (reviewed in Rummel, 2016). Multiple isoforms of 275 the synaptic vesicle protein-2 (SV2) function as the protein receptors for BoNT/A, BoNT/E 276 and BoNT/F (Rummel, 2016), whilst BoNT/C and BoNT/D seem to utilize only gangliosides 
as host cell receptors (Karalewitz et al., 2012). Due to its recent discovery, no protein receptor has been described for BoNT/X (Zhang et al., 2017). Crucially, Harper et al. found that BoNT/A is internalised in a SV subpopulation that is not destined for recycling, highlighting the existence of functional heterogeneity between SV pools (Harper et al., 2016).

BoNT/A, similar to TeNT, is able to enter neurons when SV recycling is blocked (Restani et al., 2012a), suggesting that BoNT/A could potentially use alternative entry route(s) targeting this neurotoxin to sites other than the NMJ (Figure 1B). In agreement, BoNT/A has been shown to be retrogradely transported in hippocampal, tectal and motor neurons and undergo transcytosis in the visual system (Bomba-Warczak et al., 2016; Mazzocchio and Caleo, 2015). Additionally, BoNT/A accumulates in dorsal root ganglia upon injection in the bladder (Papagiannopoulou et al., 2016). Although SV2A can potentially undergo long-range transport in spinal cord motor neurons (Debaisieux et al., 2016), other protein receptors may be involved in this process. One such protein whose endogenous trafficking route might be exploited by BoNT/A is the fibroblast growth factor receptor-3 (FGFR3). Although controversial (Weisemann et al., 2016), FGFR3 has been shown to bind BoNT/A (Jacky et al., 2013). FGFR3 undergoes receptor-mediated endocytosis (Haugsten et al., 2011) and has been identified in the proteome of axonal signalling endosomes (Debaisieux et al., 2016), thus suggesting an alternative transport route for BoNT/A. On the other hand, BoNT/A might bind to the basal membrane at the NMJ, as recently reported for TeNT (Bercsenyi et al., 2014), leading to its sorting to axonal signalling endosomes and transcytosis.

To reach its final site of action, TeNT must enter two different types of neurons: a motor neuron innervating skeletal muscle followed by an inhibitory interneuron of the spinal cord (Figure 1A,B,D). Post-internalisation, TeNT is sorted to different intracellular pathways, hence it is expected to bind to distinct receptors in these neurons. Several lines of evidence indicate that TeNT and BoNTs are internalised via different routes. First, TeNT at physiological concentrations does not block synaptic transmission at the NMJ, unlike BoNTs.

303 Second, if TeNT binding sites were present in recycling SVs, then an increase in the rate of 304 neuronal stimulation should lead to increased binding of the toxin to the membrane. This, 305 however, is not observed. While high frequency stimulation increases the rate of TeNT 306 intoxication, it does not enhance binding of the toxin to the NMJ (Schmitt et al., 1981). Third, 307 the abrogation of exocytosis and neurotransmitter release from NMJs by BoNT treatment does not affect the uptake and retrograde axonal transport of TeNT (Habermann and 309 Erdmann, 1978). Fourth, TeNT exhibits temperature-sensitive binding and internalisation; while fully functional at $25^{\circ} \mathrm{C}$, it is inactive on NMJs at $18^{\circ} \mathrm{C}$ even in the presence of highfrequency stimulation and massive neurotransmitter release (Schmitt et al., 1981). 
312 Due to the presence of two ganglioside-binding sites in the $\mathrm{H}_{\mathrm{C}}$ domain of TeNT, it was 313 proposed to rely solely on lipid binding for its cellular entry (Chen et al., 2009). Cis314 interactions of gangliosides have been suggested to play an important role in mediating 315 binding of the neurotoxin to target cells (Rinaldi et al., 2009). However, since 316 polysialogangliosides are not uniquely distributed at the NMJ and are not readily internalised 317 (Deinhardt et al., 2006a), TeNT would require additional factors to enter into motor neurons.

318 One of the proteins described to interact with TeNT is Thy-1, an abundant GPI-anchored 319 protein (Herreros et al., 2001). However, Thy-1 is unlikely to be the main protein receptor on 320 motor neurons in vivo because mice lacking Thy-1 remain sensitive to the toxic effects of 321 TeNT (Herreros et al., 2001). TeNT enters motor neurons together with the neurotrophin 322 receptors TrkB and p75 ${ }^{\mathrm{NTR}}$ (Deinhardt et al., 2006b; Terenzio et al., 2014a; Terenzio et al., 323 2014b), and its internalisation is dependent on neurotrophin signalling. Interestingly, TeNT 324 interacts with specific basal membrane components at the NMJ to stimulate uptake of TrkB 325 and formation of signalling endosomes (Bercsenyi et al., 2014). In particular, the $\mathrm{H}_{\mathrm{C}}$ domain 326 of TeNT $\left(\mathrm{H}_{\mathrm{C}} \mathrm{T}\right)$ directly binds to nidogen-1 and -2 (also known as entactin-1 and -2 ) and 327 selectively targets NMJs rich in nidogen-2. A small peptide derived from nidogen-1 blocks 328 TeNT uptake in motor neurons and at NMJs, and protects mice from TeNT-induced paralysis 329 (Bercsenyi et al., 2014). Nidogen-2 knockout mice are less sensitive to tetanus intoxication 330 and show TeNT-mediated botulism-like symptoms (Bercsenyi et al., 2014), which are also 331 observed when TeNT is injected in wild type animals at high doses (Matsuda et al., 1982). 332 Taken together, these results suggest that TeNT and BoNTs might share common entry 333 routes when key basal membrane components required by TeNT are absent or when its 334 preferred internalisation pathway is overloaded. Accordingly, addition of recombinant 335 nidogen-1 decreases the co-localisation of $H_{C} T$ with SV2A and increases its rate of 336 internalisation, whilst at high concentrations, $\mathrm{H}_{\mathrm{C}} \mathrm{T}$ preferentially enters SV2A-positive 337 organelles (Bercsenyi et al., 2014). Although controversial (Blum et al., 2012), TeNT was 338 also shown to bind SV2 in hippocampal neurons and relied on this interaction for cell entry 339 (Yeh et al., 2010).

340 The identification of protein co-receptors for TeNT at the NMJ provides crucial information on 341 this trafficking pathway from the NMJ to spinal cord interneurons, offering new strategies for 342 the delivery of therapeutics into the spinal cord. Furthermore, it provides new insights into the 343 alternative trafficking pathway used by BoNT/A to elicit responses in the CNS (Caleo and 344 Schiavo, 2009). Although further studies are required to determine whether BoNTs engage 345 with basal membrane components, these findings open the possibility that extracellular 346 matrix-derived peptides might be used to mitigate some of the undesired long-range effects 347 of BoNT/A therapy in humans. 


\section{Neuronal internalisation and axonal transport}

350 Endocytosis of CNTs is an active process: their cellular entry is temperature- and energy351 dependent and is differentially modulated by synaptic activity (Baldwin and Barbieri, 2007; 352 Blum et al., 2014; Pirazzini et al., 2017; Rummel et al., 2009). At physiological 353 concentrations, uptake of both CNTs occurs via distinct mechanisms with TeNT 354 internalisation predominantly occurring through clathrin-mediated endocytosis whilst BoNTs 355 exploit SV recycling (Blum et al., 2012; Deinhardt et al., 2006a; Montal, 2010). TeNT 356 internalisation is dependent on a specific subset of clathrin adaptors, which target the 357 neurotoxin to non-acidified endosomal compartments (Bohnert and Schiavo, 2005), thus 358 preventing the translocation of the $L$ chain into the cytoplasm of the motor neuron and 359 enabling its arrival in a fully active form to spinal cord inhibitory interneurons. Internalisation 360 of BoNT/A and TeNT is partially abrogated by dynamin inhibitors (Deinhardt et al., 2006a; 361 Harper et al., 2011) or dynamin mutant overexpression (Deinhardt et al., 2006a), in 362 agreement with the established role of dynamins in the fission of clathrin-coated vesicles 363 from the plasma membrane.

364 Although TeNT and its atoxic $\mathrm{H}$ chain fragment $\left(\mathrm{H}_{\mathrm{C}} \mathrm{T}\right)$ uptake in motor neurons is largely 365 unaffected by membrane depolarisation (Deinhardt et al., 2006a), their mechanism of entry in 366 central neurons is likely to be dependent on SV recycling. Experiments by Blum et al. 367 indicate that $\mathrm{H}_{\mathrm{C}} \mathrm{T}$ entry in cortical neurons is stimulated by membrane depolarisation (Blum et 368 al., 2014), validating previous results that show TeNT internalisation in hippocampal neurons 369 follows SV re-uptake (Matteoli et al., 1996). However, subtle differences may exist between $370 \quad \mathrm{H}_{\mathrm{C}} \mathrm{T}$ and TeNT uptake and trafficking in cortical and spinal cord neurons, as recently reported 371 (Blum et al., 2014).

372 Post-internalisation, TeNT must undergo long-range transport to reach the soma of motor 373 neurons, from where it undergoes trans-synaptic transfer into inhibitory interneurons. In order 374 to achieve this, it exploits endogenous microtubule-based axonal transport pathways which 375 the neuron uses to communicate between the synapse and the soma (Goldstein and Yang, 376 2000) (Figure 1C). This highly regulated, long-range axonal transport is facilitated by two classes of microtubule-dependent molecular motors: cytoplasmic dynein and kinesins.

378 Cytoplasmic dynein motor proteins are responsible for moving cargo in the retrograde 379 direction from axonal terminals to the cell body, where the minus ends of microtubules are 380 located. In contrast, kinesin motor proteins are responsible for delivering their cargo in the 381 anterograde direction toward the plus end of microtubules that are located in synaptic 382 terminals or growth cones (Hirokawa et al., 2010; Vale, 2003). Despite the majority of 
transport dynamics involving microtubules (Hirokawa et al., 2010), actin-based motors (e.g., myosins) also contribute and hence, some form of interactions between the microtubule- and actin-mediated transport systems has been suggested (Hirokawa et al., 2010; Vale, 2003). Cytoplasmic dynein plays a particularly crucial role in the retrograde transport of TeNT to the soma (Lalli et al., 2003; Schiavo et al., 2013) (Figure 1C). In vivo studies using mice carrying a mutation in cytoplasmic dynein heavy chain showed deficits in axonal retrograde transport of $\mathrm{H}_{\mathrm{C}} \mathrm{T}$, which are associated with motor and sensory neuron degeneration (Hafezparast et al., 2003). Functional axonal transport is crucial for the development and maintenance of the nervous system, and impairments in this process are associated with neurodegenerative conditions, such as amyotrophic lateral sclerosis (ALS) and Alzheimer's disease and acquired peripheral neuropathies (De Vos and Hafezparast, 2017; Schiavo et al., 2013). However, for cargo to bind, dynein must form a complex with dynactin and this formation is dependent on the Bicaudal $D$ (BICD) family of adaptor proteins that are enriched at the minus-end of microtubules (Carter et al., 2016; Hoogenraad and Akhmanova, 2016). Underpinning their importance, BICD1 is involved in the trafficking of TeNT and neurotrophinreceptor complexes (Schmieg et al., 2014; Terenzio et al., 2014b) and mutations in the homologous BICD2 have been shown to cause spinal muscular atrophy (Oates et al., 2013; Rossor et al., 2015).

The retrograde transport of $\mathrm{H}_{\mathrm{C}} \mathrm{T}$ takes place in axonal signalling endosomes, which contain neurotrophins, their receptors and other proteins (Deinhardt et al., 2006b; Lalli and Schiavo, 2002). To create a functional physical map of these organelles, our laboratory has developed a method based on magnetic iron oxide nanoparticles coupled to $H_{C} T$, which enable the purification of signalling endosomes from embryonic stem cell-derived motor neurons and their quantitative mass spectrometry analysis (Debaisieux et al., 2016; Deinhardt et al., 2006b; Wade et al., 2012). We found that $\mathrm{H}_{\mathrm{C}} \mathrm{T}$-positive organelles undergo rapid maturation with the acquisition of late endosomal markers, and are specifically enriched in proteins known to be involved in neurodegenerative diseases and neuroinfection (Debaisieux et al., 2016). The maturation of signalling endosomes is dependent upon Rab5, which is involved in sorting after internalisation, followed by Rab7, which is involved in the fast retrograde transport of HcT (Figure 1C) as well as neurotrophin-receptor complexes (Deinhardt et al., 2006b; Salinas et al., 2009). A functional cross-talk between $H_{C} T$ and neurotrophins is emerging, since the application of exogenous brain-derived neurotrophic factor (BDNF) results in an increase in the internalisation of $\mathrm{HcT}$ at the $\mathrm{NMJ}$ as well as accumulation of $\mathrm{HcT}$

416 in the sciatic nerve (Roux et al., 2006). However, the sharing of axonal signalling endosomes 417 by other virulence/pathological factors such as canine adenovirus-2, cholera toxin, poliovirus, 418 Borna virus and pseudotyped lentivirus with neurotrophin receptors suggests that despite 
different methods of internalisation, a common mechanism for sorting and retrograde transport may exist (Charlier et al., 2016; Hislop et al., 2014; Ohka et al., 2009; Salinas et al., 421 2009).

422 In contrast to the acidic $\mathrm{pH}$ found in the lumen of the majority of endosomes, axonal transport carriers containing $\mathrm{H}_{\mathrm{C}} \mathrm{T}$ display neutral $\mathrm{pH}$. The $\mathrm{pH}$ of signalling endosomes is critical, as acidification in TeNT and BoNTs carriers triggers the translocation of the enzymatically active subunit (i.e., L chain) into the cytosol. Endosomal acidification also causes the dissociation of neurotrophin-receptor complexes, terminates their en route signalling and targets the endosome for degradation. Such tight regulation of the $\mathrm{pH}$ is dependent on the vacuolar ATPase complex (Bohnert and Schiavo, 2005). Therefore, the maintenance of neutral $\mathrm{pH}$ of TeNT carriers enables its presentation to interneurons in a fully active form to consequently mediate the disruption of synaptic communication.

431 In contrast to the historical view that BoNTs only disrupt communication at the NMJ, several studies provide evidence of long-range trafficking and CNS expression of BoNT after intramuscular injections (reviewed in Caleo and Schiavo, 2009; Mazzocchio and Caleo, 2015). Indeed, BoNT/A was first detected in the spinal cord ventral horn after injections in the gastrocnemius muscle (Wiegand et al., 1976). Its presence was also detected in diaphragms after intraperitoneal injections of BoNT/A and /B (Black and Dolly, 1986). In this context, higher BoNT/A levels were observed in the axoplasm of myelinated axons, suggestive of differences in the uptake and sorting mechanisms of different BoNT serotypes (Black and Dolly, 1986). Experiments comparing the effects of BoNT/A and /E applied to the distal neurites of primary sympathetic neurons cultured in compartmentalised chambers revealed that whilst most BoNT/A and /E cleaved SNAP25 near the sight of uptake, a small fraction also cleaved SNAP25 in their soma, albeit at different rates (Lawrence et al., 2012). In addition, Restani et al. have demonstrated that BoNT/A undergoes fast axonal retrograde transport whereas BoNT/E exhibited slower axonal retrograde transport with a greater frequency of pausing and short periods of anterograde transport in primary motor neurons

446 (Restani et al., 2012a). This study suggests that BoNT/E is coupled with a less efficient 447 mechanism of long-range trafficking and may explain, in part, why BoNT/E cannot mediate 448 similar effects in the CNS, despite having the same intracellular targets as BoNT/A. 449 Furthermore, these data also suggest that the serotype and concentration of BoNTs are also 450 key factors in local (i.e., NMJ) versus distant (i.e., soma) effects. These results were 451 confirmed in hippocampal neurons grown in microfluidic devices, where BoNT/A and BoNT/D 452 were found to be taken up into non-acidified organelles undergoing axonal retrograde 453 transport to the soma (Bomba-Warczak et al., 2016). After internalisation, their activities were 454 detected in upstream neurons, thus indicating that BoNT/A, BoNT/D and TeNT may undergo 
interneuronal transfer in an active form in vitro (Bomba-Warczak et al., 2016). Interestingly, Wang et al. found that a significant proportion of $H_{C}$ fragment of BoNT/A $\left(H_{C} A\right)$ was incorporated into LC3-positive autophagosomes in hippocampal neurons, which then underwent retrograde transport to the cell soma. Blocking autophagosome formation or acidification inhibited the activity-dependent retrograde trafficking of $\mathrm{H}_{\mathrm{C}} \mathrm{A}$, suggesting a role for presynaptic autophagosomes in long distance transport of BoNT/A (Wang et al., 2015). Elements of this process have been recapitulated in vivo by studies demonstrating the retrograde transport of BoNT/A and $\mathrm{H}_{\mathrm{C}} \mathrm{A}$ in spinal cord motor neurons (Antonucci et al., 2008; Restani et al., 2012a; Restani et al., 2012b; Wang et al., 2015) and sensory neurons (Fan et al., 2017; Hong et al., 2017; Matak et al., 2014; Papagiannopoulou et al., 2016). Taken altogether, these investigations provide evidence that BoNTs also undergo retrograde transport to the CNS, the consequences of which are yet to be entirely understood.

\subsection{Future perspectives}

Since TeNT and BoNTs are capable of being sorted to the axonal retrograde trafficking route and undergo interneuronal transfer in vivo, it has been proposed that non-toxic fragments of CNTs may be used as targeting agents for the delivery of therapeutics, such as recombinant proteins and/or DNA, into the CNS (Toivonen et al., 2010). Chimeras of $\mathrm{H}_{\mathrm{C}} \mathrm{T}$ and various proteins have been shown to be successfully internalised and undergo axonal retrograde transport, maintaining their enzymatic activity upon delivery to the targeted area (Francis et al., 2004a). Importantly, these $\mathrm{H}_{\mathrm{C}} \mathrm{T}$ fusion proteins were shown to transfer across synapses in vivo (Coen et al., 1997), access second and higher-order neurons (Miana-Mena et al., 2003) and deliver their payload to the neuronal cytosol, when fused to translocationcompetent proteins (e.g. diphtheria toxin) (Francis et al., 2004b).

Due to their diverse biological activities, neuronal growth factors have frequently been used as biological payloads. BDNF and glial cell line-derived neurotrophic factor (GDNF) fused with $\mathrm{H}_{\mathrm{C}} \mathrm{T}$ have been found to have neuroprotective effects in animal models of ALS (Calvo et al., 2011; Ciriza et al., 2008) and Parkinson's disease (Larsen et al., 2006). Fusion of cardiotrophin-1 and $\mathrm{H}_{\mathrm{C}} \mathrm{T}$ also promoted motor neuron survival (Bordet et al., 2001), whilst a chimera of the anti-apoptotic factor $\mathrm{Bcl}-\mathrm{XL}$ and $\mathrm{H}_{\mathrm{C}} \mathrm{T}$ decreased apoptosis induced by glutamate-mediated excitotoxicity (Carlton et al., 2008). BDNF has also been targeted to neurons by nanoparticles made of polyethylene imine linked to $H_{C} T$ (Oliveira et al., 2010).

Protein engineering has been explored to re-target BoNTs to different neuronal populations by using a self-assembling 'protein stapling' technology (Ferrari et al., 2013). BoNT/A lacking its $H_{C} A$ domain as well as $H_{C} T$ were produced separately and then linked by exploiting the 
high-affinity interaction of paired SNARE motifs (Ferrari et al., 2013). The stapled chimera was found to lack peripheral paralytic effects, and significantly reduce the enhanced nociceptive sensitivity found in animal models of inflammatory, surgical, and neuropathic pain (Mangione et al., 2016).

Whilst these studies have explored the potential of recombinant protein chimeras, a few attempts have been made to directly express these fusion proteins by delivering exogenous DNA. In particular, Moreno-lgoa et al. showed that a single intramuscular administration of naked-DNA encoding GDNF- $\mathrm{H}_{\mathrm{C}} \mathrm{T}$ significantly delayed the onset of symptoms, ameliorate the functional deficits and extended the lifespan of a mouse model of ALS (Moreno-Igoa et al., 2012). $\mathrm{H}_{\mathrm{C}} \mathrm{T}$ might thus represent a valuable strategy to deliver therapeutics to the CNS by exploiting its high tropism for motor neurons and its ability to undergo axonal retrograde transport and transcytosis. In addition, DNA fusion vaccines encoding a portion of $\mathrm{H}_{\mathrm{C}} \mathrm{T}$ coupled with tumour antigen sequences is highly immunogenic against colon carcinoma (Behzadi et al., 2016).

Several studies have also highlighted the intrinsic ability of $\mathrm{H}_{\mathrm{C}} \mathrm{T}$ to protect neurons from neurodegeneration in a variety of animal models, including chemically induced Parkinson's disease (Mendieta et al., 2009), ALS (Moreno-Igoa et al., 2010) and spinal muscular atrophy (Olivan et al., 2016). This property may be linked to the ability of $H_{C} T$ to activate the neurotrophin receptor signalling cascade, including ERK1/2 and Akt, via a mechanism still not completely understood (Gil et al., 2003; Gil et al., 2001). $\mathrm{H}_{\mathrm{C}} \mathrm{T}$ co-localises with the neurotrophin receptors TrkB and $\mathrm{p} 75^{\mathrm{NTR}}$ in axonal signalling endosomes (Deinhardt et al., 2006a; Lalli and Schiavo, 2002), yet it is unclear whether $H_{C} T$ signalling is physiologically relevant and whether it would negatively or positively regulate axonal retrograde transport. However, recent results from Wang et al. demonstrate that TrkB activation couples synaptic activity with the retrograde flux of axonal signalling endosomes, thus suggesting that $\mathrm{H}_{\mathrm{C}} \mathrm{T}$ and TeNT regulate their own sorting and/or retrograde transport (Wang et al., 2016).

In addition to their importance as virulence factors and biotherapeutics, BoNTs, TeNT and their recombinant fragments are also becoming increasingly popular as key tools of discovery to uncover deficits of axonal transport in animal models of neurological diseases (Bilsland et al., 2010; LeRoux et al., 2014; Malik et al., 2011; Schafer et al., 2017; Sleigh et al., 2017a; Sleigh et al., 2017b), ageing (Sleigh and Schiavo, 2016) and as flexible transsynaptic tracers (Coen et al., 1999; Kumar and Boehm, 2014).

Several important questions centred on the trafficking of BoNTs and TeNT are still unaddressed. First and foremost, the nature of the receptor complex targeting TeNT and BoNTs to axonal signalling endosomes at the NMJ need to be elucidated at the molecular 
525 level, together with the exact role of neurotrophin signalling (or other signalling cascades) in

526 this process. This line of research would help the identification of the minimal requirements

527 for the efficient sorting of these neurotoxins to proximal and/or distal sites of action. This

528 information would be important for basic and clinical scientists to direct the in vivo activity of

529 BoNTs, thus improving their clinical specificity and limiting their side effects. Further research

530 is also necessary to define the neuronal receptors of the expanding family of BoNT subtypes

531 (Peck et al., 2017) and their preferential site of action in vivo. This in turn would allow the

532 selection of novel BoNT subtypes endowed with unique pharmacodynamics and

533 pharmacokinetics properties ideal for specific clinical applications (e.g. chronic pain, short

534 term treatment in post-operative management). In this way, the travel diaries of TeNT and

535 BoNTs would become not just a fascinating reading for molecular and cellular

536 neurobiologists, but a very useful roadmap for pharmacologists and clinical neuroscientists to

537 understand, navigate and treat the human nervous system.

538

\section{7. Acknowledgements}

540 We thank James N. Sleigh (UCL Institute of Neurology) for critical reading of the manuscript.

541 This work was supported by the Human Frontier Science Program (LT000220/2017-L) (SS),

542 the MRC Centre for Neuromuscular Diseases and UCL Grand Challenge Studentship (IM),

543 the Wolfson Foundation (ADF), the Wellcome Trust Senior Investigator Award

544 (107116/Z/15/Z) (AT, SS, IM, SN, GS), the European Union's Horizon 2020 Research and

545 Innovation programme under grant agreement 739572 (GS), and a UK Dementia Research

546 Institute Foundation award (GS). 


\section{References}

549 Amatsu, S., Sugawara, Y., Matsumura, T., Kitadokoro, K., Fujinaga, Y., 2013. Crystal 550 structure of Clostridium botulinum whole hemagglutinin reveals a huge triskelion-shaped 551 molecular complex. J. Biol. Chem. 288, 35617-35625.

552

553

554

Antonucci, F., Rossi, C., Gianfranceschi, L., Rossetto, O., Caleo, M., 2008. Long-distance retrograde effects of botulinum neurotoxin A. J. Neurosci. 28, 3689-3696.

Azarnia Tehran, D., Pirazzini, M., Leka, O., Mattarei, A., Lista, F., Binz, T., Rossetto, O., Montecucco, C., 2017. Hsp90 is involved in the entry of clostridial neurotoxins into the cytosol of nerve terminals. Cell. Microbiol. in press

Bagetta, G., Knott, C., Nistico, G., Bowery, N.G., 1990. Tetanus toxin produces neuronal loss and a reduction in GABAA but not GABAB binding sites in rat hippocampus. Neurosci. Lett. 109, 7-12.

Baldwin, M.R., Barbieri, J.T., 2007. Association of botulinum neurotoxin serotypes a and B with synaptic vesicle protein complexes. Biochemistry 46, 3200-3210.

Behzadi, E., Halabian, R., Hosseini, H.M., Fooladi, A.A., 2016. Bacterial toxin's DNA vaccine serves as a strategy for the treatment of cancer, infectious and autoimmune diseases. Microb. Pathog. 100, 184-194.

Bercsenyi, K., et al., 2014. Tetanus toxin entry. Nidogens are therapeutic targets for the prevention of tetanus. Science 346, 1118-1123.

Bhattacharyya, S.D., Sugiyama, H., 1989. Inactivation of botulinum and tetanus toxins by chelators. Infect. Immun. 57, 3053-3057.

Bigalke, H., Muller, H., Dreyer, F., 1986. Botulinum A neurotoxin unlike tetanus toxin acts via a neuraminidase sensitive structure. Toxicon 24, 1065-1074.

Bilsland, L.G., Sahai, E., Kelly, G., Golding, M., Greensmith, L., Schiavo, G., 2010. Deficits in axonal transport precede ALS symptoms in vivo. Proc. Natl. Acad. Sci. U. S. A. 107, 2052320528.

Black, J.D., Dolly, J.O., 1986. Interaction of 125I-labeled botulinum neurotoxins with nerve terminals. I. Ultrastructural autoradiographic localization and quantitation of distinct membrane acceptors for types A and B on motor nerves. J. Cell Biol. 103, 521-534.

Blum, F.C., Chen, C., Kroken, A.R., Barbieri, J.T., 2012. Tetanus Toxin and Botulinum Toxin A Utilize Unique Mechanisms To Enter Neurons of the Central Nervous System. Infect. Immun. 80, 1662-1669.

Blum, F.C., Tepp, W.H., Johnson, E.A., Barbieri, J.T., 2014. Multiple domains of tetanus toxin direct entry into primary neurons. Traffic 15, 1057-1065.

Bohnert, S., Schiavo, G., 2005. Tetanus toxin is transported in a novel neuronal compartment characterized by a specialized pH regulation. J. Biol. Chem. 280, 42336-42344. 
Bomba-Warczak, E., Vevea, J.D., Brittain, J.M., Figueroa-Bernier, A., Tepp, W.H., Johnson, 585 E.A., Yeh, F.L., Chapman, E.R., 2016. Interneuronal Transfer and Distal Action of Tetanus 586 Toxin and Botulinum Neurotoxins A and D in Central Neurons. Cell Rep 16, 1974-1987.

Bordet, T., Castelnau-Ptakhine, L., Fauchereau, F., Friocourt, G., Kahn, A., Haase, G., 2001. Neuronal targeting of cardiotrophin-1 by coupling with tetanus toxin $C$ fragment. Mol. Cell. Neurosci. 17, 842-854.

Bowery, N.G., Bagetta, G., Nistico, G., Britton, P., Whitton, P., 1992. Intrahippocampal tetanus toxin produces generalized convulsions and neurodegeneration in rats: antagonism by NMDA receptor blockers. Epilepsy Res. Suppl. 9, 249-256.

Breidenbach, M.A., Brunger, A.T., 2005. 2.3 A crystal structure of tetanus neurotoxin light chain. Biochemistry 44, 7450-7457.

Caleo, M., Schiavo, G., 2009. Central effects of tetanus and botulinum neurotoxins. Toxicon 54, 593-599.

Calvo, A.C., et al., 2011. Lack of a synergistic effect of a non-viral ALS gene therapy based on BDNF and a TTC fusion molecule. Orphanet J. Rare Dis. 6, 10.

Carlton, E., Teng, Q., Federici, T., Yang, J., Riley, J., Boulis, N.M., 2008. Fusion of the tetanus toxin $\mathrm{C}$ fragment binding domain and $\mathrm{BCl}-\mathrm{xL}$ for protection of peripheral nerve neurons. Neurosurgery 63, 1175-1184.

Charlier, C.M., Debaisieux, S., Foret, C., Thouard, A., Schiavo, G., Gonzalez-Dunia, D., Malnou, C.E., 2016. Neuronal retrograde transport of Borna disease virus occurs in signalling endosomes. J. Gen. Virol. 97, 3215-3224.

Chen, C., Fu, Z.J., Kim, J.J.P., Barbieri, J.T., Baldwin, M.R., 2009. Gangliosides as High Affinity Receptors for Tetanus Neurotoxin. J. Biol. Chem. 284, 26569-26577.

Ciriza, J., et al., 2008. A genetic fusion GDNF-C fragment of tetanus toxin prolongs survival in a symptomatic mouse ALS model. Restor. Neurol. Neurosci. 26, 459-465.

Coen, L., Kissa, K., le Mevel, S., Brulet, P., Demeneix, B.A., 1999. A somatic gene transfer approach using recombinant fusion proteins to map muscle-motoneuron projections in Xenopus spinal cord. Int. J. Dev. Biol. 43, 823-830.

Coen, L., Osta, R., Maury, M., Brulet, P., 1997. Construction of hybrid proteins that migrate retrogradely and transynaptically into the central nervous system. Proc. Natl. Acad. Sci. U. S. A. $94,9400-9405$.

Cordero-Erausquin, M., Allard, S., Dolique, T., Bachand, K., Ribeiro-da-Silva, A., De Koninck, Y., 2009. Dorsal horn neurons presynaptic to lamina I spinoparabrachial neurons revealed by transynaptic labeling. J. Comp. Neurol. 517, 601-615.

de Paiva, A., Poulain, B., Lawrence, G.W., Shone, C.C., Tauc, L., Dolly, J.O., 1993. A role for the interchain disulfide or its participating thiols in the internalization of botulinum 
neurotoxin $A$ revealed by a toxin derivative that binds to ecto-acceptors and inhibits transmitter release intracellularly. J. Biol. Chem. 268, 20838-20844.

De Vos, K.J., Hafezparast, M., 2017. Neurobiology of axonal transport defects in motor neuron diseases: Opportunities for translational research? Neurobiol. Dis., DOI: 10.1016/j.nbd.2017.1002.1004.

Debaisieux, S., Encheva, V., Chakravarty, P., Snijders, A.P., Schiavo, G., 2016. Analysis of Signaling Endosome Composition and Dynamics Using SILAC in Embryonic Stem CellDerived Neurons. Mol. Cell. Proteomics 15, 542-557.

Deinhardt, K., Berninghausen, O., Willison, H.J., Hopkins, C.R., Schiavo, G., 2006a. Tetanus toxin is internalized by a sequential clathrin-dependent mechanism initiated within lipid microdomains and independent of epsin 1. J. Cell Biol. 174, 459-471.

Deinhardt, K., Salinas, S., Verastegui, C., Watson, R., Worth, D., Hanrahan, S., Bucci, C., Schiavo, G., 2006b. Rab5 and Rab7 control endocytic sorting along the axonal retrograde transport pathway. Neuron 52, 293-305. 122

Ferecsko, A.S., Jiruska, P., Foss, L., Powell, A.D., Chang, W.C., Sik, A., Jefferys, J.G., 2015. Structural and functional substrates of tetanus toxin in an animal model of temporal lobe epilepsy. Brain Struct Funct 220, 1013-1029.

Francis, J.W., Bastia, E., Matthews, C.C., Parks, D.A., Schwarzschild, M.A., Brown, R.H., Jr., Fishman, P.S., 2004a. Tetanus toxin fragment $C$ as a vector to enhance delivery of proteins to the CNS. Brain Res. 1011, 7-13.

Francis, J.W., et al., 2004b. A survival motor neuron:tetanus toxin fragment $C$ fusion protein for the targeted delivery of SMN protein to neurons. Brain Res. 995, 84-96.

Garcia-Rodriguez, C., Levy, R., Arndt, J.W., Forsyth, C.M., Razai, A., Lou, J., Geren, I., 648 Stevens, R.C., Marks, J.D., 2007. Molecular evolution of antibody cross-reactivity for two subtypes of type A botulinum neurotoxin. Nat. Biotechnol. 25, 107-116. chain activates Akt and MEK/ERK signalling pathways in a Trk receptor-dependent manner 
Goldstein, L.S., Yang, Z., 2000. Microtubule-based transport systems in neurons: the roles of Rummel, A., Jin, R., 2012. Botulinum neurotoxin is shielded by NTNHA in an interlocked complex. Science 335, 977-981.

Habermann, E., 1989. Clostridial neurotoxins and the central nervous system: sunctional studies on isolated preparations, in: Simpson, L.L. (Ed.), Botulinum neurotoxins and tetanus toxin. Academic Press, San Diego.

Habermann, E., Erdmann, G., 1978. Pharmacokinetic and histoautoradiographic evidence for

Hafezparast, M., et al., 2003. Mutations in dynein link motor neuron degeneration to defects in retrograde transport. Science $300,808-812$.

Herreros, J., Ng, T., Schiavo, G., 2001. Lipid rafts act as specialized domains for tetanus mechanisms and roles in brain function, development, and disease. Neuron 68, 610-638.

Hislop, J.N., Islam, T.A., Eleftheriadou, I., Carpentier, D.C., Trabalza, A., Parkinson, M., vectors to the axonal retrograde pathway in motor neurons. J. Biol. Chem. 289, 1614816163. neurons. Neuroscience 357, 197-207. 
Karalewitz, A.P., Fu, Z., Baldwin, M.R., Kim, J.J., Barbieri, J.T., 2012. Botulinum neurotoxin serotype $C$ associates with dual ganglioside receptors to facilitate cell entry. J. Biol. Chem. 287, 40806-40816.

Kitamura, M., Igimi, S., Furukawa, K., Furukawa, K., 2005. Different response of the knockout mice lacking b-series gangliosides against botulinum and tetanus toxins. Biochim. Biophys. Acta 1741, 1-3.

Kitamura, M., Iwamori, M., Nagai, Y., 1980. Interaction between Clostridium botulinum neurotoxin and gangliosides. Biochim. Biophys. Acta 628, 328-335.

Kumar, D., Boehm, U., 2014. Conditional genetic transsynaptic tracing in the embryonic mouse brain. J Vis Exp. DOI: 10.3791/52487.

Kumaran, D., Eswaramoorthy, S., Furey, W., Navaza, J., Sax, M., Swaminathan, S., 2009. Domain organization in Clostridium botulinum neurotoxin type $E$ is unique: its implication in faster translocation. J. Mol. Biol. 386, 233-245.

Lacy, D.B., Stevens, R.C., 1999. Sequence homology and structural analysis of the clostridial neurotoxins. J. Mol. Biol. 291, 1091-1104.

Lacy, D.B., Tepp, W., Cohen, A.C., DasGupta, B.R., Stevens, R.C., 1998. Crystal structure of botulinum neurotoxin type A and implications for toxicity. Nat. Struct. Biol. 5, 898-902.

Lalli, G., Bohnert, S., Deinhardt, K., Verastegui, C., Schiavo, G., 2003. The journey of tetanus and botulinum neurotoxins in neurons. Trends Microbiol. 11, 431-437.

Lalli, G., Herreros, J., Osborne, S.L., Montecucco, C., Rossetto, O., Schiavo, G., 1999. Functional characterisation of tetanus and botulinum neurotoxins binding domains. J. Cell Sci. 112 2715-2724.

Lalli, G., Schiavo, G., 2002. Analysis of retrograde transport in motor neurons reveals common endocytic carriers for tetanus toxin and neurotrophin receptor p $75^{\mathrm{NTR}}$. J. Cell Biol. $156,233-239$.

Larsen, K.E., et al., 2006. A glial cell line-derived neurotrophic factor (GDNF):tetanus toxin fragment $\mathrm{C}$ protein conjugate improves delivery of GDNF to spinal cord motor neurons in mice. Brain Res. 1120, 1-12.

Lawrence, G.W., Ovsepian, S.V., Wang, J., Aoki, K.R., Dolly, J.O., 2012. Extravesicular intraneuronal migration of internalized botulinum neurotoxins without detectable inhibition of distal neurotransmission. Biochem. J. 441, 443-452.

Lee, K., et al., 2013. Structure of a bimodular botulinum neurotoxin complex provides insights into its oral toxicity. PLoS Pathog. 9, e1003690.

Lee, K., Zhong, X., Gu, S., Kruel, A.M., Dorner, M.B., Perry, K., Rummel, A., Dong, M., Jin, R., 2014. Molecular basis for disruption of E-cadherin adhesion by botulinum neurotoxin $A$ complex. Science 344, 1405-1410. 
LeRoux, L.G., Bredow, S., Grosshans, D., Schellingerhout, D., 2014. Molecular imaging detects impairment in the retrograde axonal transport mechanism after radiation-induced spinal cord injury. Mol. Imaging Biol. 16, 504-510.

Malik, B., Nirmalananthan, N., Bilsland, L.G., La Spada, A.R., Hanna, M.G., Schiavo, G., Gallo, J.M., Greensmith, L., 2011. Absence of disturbed axonal transport in spinal and bulbar muscular atrophy. Hum. Mol. Genet. 20, 1776-1786.

Mangione, A.S., Obara, I., Maiaru, M., Geranton, S.M., Tassorelli, C., Ferrari, E., Leese, C., Davletov, B., Hunt, S.P., 2016. Nonparalytic botulinum molecules for the control of pain. Pain $157,1045-1055$.

Marie, A., 1897. Recherche sur la toxine tetanique. Ann. Inst. Past. 11, 591-599.

Masuyer, G., Conrad, J., Stenmark, P., 2017. The structure of the tetanus toxin reveals pHmediated domain dynamics. EMBO Rep 18, 1306-1317.

Matak, I., Rossetto, O., Lackovic, Z., 2014. Botulinum toxin type A selectivity for certain types of pain is associated with capsaicin-sensitive neurons. Pain 155, 1516-1526.

Matsuda, M., Sugimoto, N., Ozutsumi, K., Hirai, T., 1982. Acute Botulinum-Like Intoxication by Tetanus Neurotoxin in Mice. Biochem Bioph Res Comm 104, 799-805.

Matteoli, M., Verderio, C., Rossetto, O., lezzi, N., Coco, S., Schiavo, G., Montecucco, C., 1996. Synaptic vesicle endocytosis mediates the entry of tetanus neurotoxin into hippocampal neurons. Proc. Natl. Acad. Sci. U. S. A. 93, 13310-13315.

Mazzocchio, R., Caleo, M., 2015. More than at the neuromuscular synapse: actions of botulinum neurotoxin $A$ in the central nervous system. Neuroscientist 21, 44-61.

Mendieta, L., Venegas, B., Moreno, N., Patricio, A., Martinez, I., Aguilera, J., Limon, I.D., 2009. The carboxyl-terminal domain of the heavy chain of tetanus toxin prevents dopaminergic degeneration and improves motor behavior in rats with striatal MPP(+)-lesions. Neurosci. Res. 65, 98-106.

Miana-Mena, F.J., Munoz, M.J., Ciriza, J., Soria, J., Brulet, P., Zaragoza, P., Osta, R., 2003. Fragment $C$ tetanus toxin: a putative activity-dependent neuroanatomical tracer. Acta Neurobiol. Exp. (Wars.) 63, 211-218.

Montal, M., 2010. Botulinum Neurotoxin: A Marvel of Protein Design. Annual Review of Biochemistry, Vol 79 79, 591-617.

Montecucco, C., 1986. How do tetanus and botulinum toxins bind to neuronal membranes. Trends Biochem. Sci. 11, 315-317.

Montecucco, C., Rossetto, O., Schiavo, G., 2004. Presynaptic receptor arrays for clostridial neurotoxins. Trends Microbiol. 12, 442-446. 

how many, how close? Trends Biochem. Sci. 30, 367-372.

Moreno-Igoa, M., Calvo, A.C., Ciriza, J., Munoz, M.J., Zaragoza, P., Osta, R., 2012. Nonviral gene delivery of the GDNF, either alone or fused to the C-fragment of tetanus toxin protein, prolongs survival in a mouse ALS model. Restor. Neurol. Neurosci. 30, 69-80.

Moreno-Igoa, M., et al., 2010. Fragment $C$ of tetanus toxin, more than a carrier. Novel perspectives in non-viral ALS gene therapy. J. Mol. Med. (Berl.) 88, 297-308.

Muraro, L., Tosatto, S., Motterlini, L., Rossetto, O., Montecucco, C., 2009. The N-terminal half of the receptor domain of botulinum neurotoxin $A$ binds to microdomains of the plasma membrane. Biochem. Biophys. Res. Commun. 380, 76-80.

Oates, E.C., et al., 2013. Mutations in BICD2 cause dominant congenital spinal muscular atrophy and hereditary spastic paraplegia. Am. J. Hum. Genet. 92, 965-973.

Ohka, S., Sakai, M., Bohnert, S., Igarashi, H., Deinhardt, K., Schiavo, G., Nomoto, A., 2009. Receptor-dependent and -independent axonal retrograde transport of poliovirus in motor neurons. J. Virol. 83, 4995-5004.

Olivan, S., Calvo, A.C., Rando, A., Herrando-Grabulosa, M., Manzano, R., Zaragoza, P., Tizzano, E.F., Aquilera, J., Osta, R., 2016. Neuroprotective Effect of Non-viral Gene Therapy Treatment Based on Tetanus Toxin C-fragment in a Severe Mouse Model of Spinal Muscular Atrophy. Front. Mol. Neurosci. 9, 76.

Oliveira, H., Fernandez, R., Pires, L.R., Martins, M.C., Simoes, S., Barbosa, M.A., Pego, A.P., 2010. Targeted gene delivery into peripheral sensorial neurons mediated by selfassembled vectors composed of poly(ethylene imine) and tetanus toxin fragment $\mathrm{c}$. J. Control. Release 143, 350-358.

Ovsepian, S.V., Bodeker, M., O'Leary, V.B., Lawrence, G.W., Oliver Dolly, J., 2015. Internalization and retrograde axonal trafficking of tetanus toxin in motor neurons and transsynaptic propagation at central synapses exceed those of its C-terminal-binding fragments. Brain Struct Funct 220, 1825-1838.

Papagiannopoulou, D., Vardouli, L., Dimitriadis, F., Apostolidis, A., 2016. Retrograde transport of radiolabelled botulinum neurotoxin type $A$ to the CNS after intradetrusor injection in rats. BJU Int. 117, 697-704.

Peck, M.W., et al., 2017. Historical Perspectives and Guidelines for Botulinum Neurotoxin Subtype Nomenclature. Toxins (Basel) 9. DOI: 10.3390/toxins9010038

Pirazzini, M., Azarnia Tehran, D., Leka, O., Zanetti, G., Rossetto, O., Montecucco, C., 2016. On the translocation of botulinum and tetanus neurotoxins across the membrane of acidic intracellular compartments. Biochim. Biophys. Acta 1858, 467-474.

Pirazzini, M., Azarnia Tehran, D., Zanetti, G., Lista, F., Binz, T., Shone, C.C., Rossetto, O., Montecucco, C., 2015. The thioredoxin reductase--Thioredoxin redox system cleaves the 
interchain disulphide bond of botulinum neurotoxins on the cytosolic surface of synaptic vesicles. Toxicon 107, 32-36.

Pirazzini, M., et al., 2014. Thioredoxin and its reductase are present on synaptic vesicles, and their inhibition prevents the paralysis induced by botulinum neurotoxins. Cell Rep 8 , 1870-1878.

Pirazzini, M., Rossetto, O., Eleopra, R., Montecucco, C., 2017. Botulinum Neurotoxins: Biology, Pharmacology, and Toxicology. Pharmacol. Rev. 69, 200-235.

Restani, L., Giribaldi, F., Manich, M., Bercsenyi, K., Menendez, G., Rossetto, O., Caleo, M., Schiavo, G., 2012a. Botulinum Neurotoxins A and E Undergo Retrograde Axonal Transport in Primary Motor Neurons. PLoS Pathog. 8, e1003087.

Restani, L., Novelli, E., Bottari, D., Leone, P., Barone, I., Galli-Resta, L., Strettoi, E., Caleo, M., 2012b. Botulinum Neurotoxin A Impairs Neurotransmission Following Retrograde Transynaptic Transport. Traffic 13, 1083-1089.

Rinaldi, S., Brennan, K.M., Goodyear, C.S., O'Leary, C., Schiavo, G., Crocker, P.R., Willison, H.J., 2009. Analysis of lectin binding to glycolipid complexes using combinatorial glycoarrays. Glycobiology 19, 789-796.

Rossetto, O., Seveso, M., Caccin, P., Schiavo, G., Montecucco, C., 2001. Tetanus and botulinum neurotoxins: turning bad guys into good by research. Toxicon 39, 27-41.

Rossor, A.M., et al., 2015. Phenotypic and molecular insights into spinal muscular atrophy due to mutations in BICD2. Brain 138, 293-310.

Roux, S., Saint Cloment, C., Curie, T., Girard, E., Mena, F.J., Barbier, J., Osta, R., Molgo, J., Brulet, P., 2006. Brain-derived neurotrophic factor facilitates in vivo internalization of tetanus neurotoxin C-terminal fragment fusion proteins in mature mouse motor nerve terminals. Eur. J. Neurosci. 24, 1546-1554.

Rummel, A., 2013. Double receptor anchorage of botulinum neurotoxins accounts for their exquisite neurospecificity. Curr. Top. Microbiol. Immunol. 364, 61-90.

Rummel, A., 2016. Two Feet on the Membrane: Uptake of Clostridial Neurotoxins. Curr. Top. Microbiol. Immunol.

Rummel, A., Bade, S., Alves, J., Bigalke, H., Binz, T., 2003. Two carbohydrate binding sites in the $\mathrm{H}_{\mathrm{CC}}$-domain of tetanus neurotoxin are required for toxicity. J. Mol. Biol. 326, 835-847.

Rummel, A., et al., 2007. Identification of the protein receptor binding site of botulinum neurotoxins B and G proves the double-receptor concept. Proc. Natl. Acad. Sci. U. S. A. 104, 359-364.

Rummel, A., et al., 2009. Botulinum neurotoxins C, E and $F$ bind gangliosides via a conserved binding site prior to stimulation-dependent uptake with botulinum neurotoxin $F$ utilising the three isoforms of SV2 as second receptor. J. Neurochem. 110, 1942-1954. 
Salinas, S., Bilsland, L.G., Henaff, D., Weston, A.E., Keriel, A., Schiavo, G., Kremer, E.J., 2009. CAR-associated vesicular transport of an adenovirus in motor neuron axons. PLoS Pathog. 5, e1000442.

Schafer, M.K., Bellouze, S., Jacquier, A., Schaller, S., Richard, L., Mathis, S., Vallat, J.M., Haase, G., 2017. Sensory neuropathy in progressive motor neuronopathy (pmn) mice is associated with defects in microtubule polymerization and axonal transport. Brain Pathol. 27, 459-471.

Schiavo, G., Greensmith, L., Hafezparast, M., Fisher, E.M., 2013. Cytoplasmic dynein heavy chain: the servant of many masters. Trends Neurosci. 36, 641-651.

Schiavo, G., Papini, E., Genna, G., Montecucco, C., 1990. An intact interchain disulfide bond is required for the neurotoxicity of tetanus toxin. Infect. Immun. 58, 4136-4141.

Schiavo, G., Poulain, B., Rossetto, O., Benfenati, F., Tauc, L., Montecucco, C., 1992a. Tetanus toxin is a zinc protein and its inhibition of neurotransmitter release and protease activity depend on zinc. EMBO J. 11, 3577-3583.

Schiavo, G., Rossetto, O., Santucci, A., DasGupta, B.R., Montecucco, C., 1992b. Botulinum neurotoxins are zinc proteins. J. Biol. Chem. 267, 23479-23483.

Schiavo, G., Shone, C.C., Bennett, M.K., Scheller, R.H., Montecucco, C., 1995. Botulinum neurotoxin type $\mathrm{C}$ cleaves a single Lys-Ala bond within the carboxyl-terminal region of syntaxins. J. Biol. Chem. 270, 10566-10570.

Schiavo, G., Shone, C.C., Rossetto, O., Alexander, F.C., Montecucco, C., 1993. Botulinum neurotoxin serotype $F$ is a zinc endopeptidase specific for VAMP/synaptobrevin. J. Biol. Chem. 268, 11516-11519.

Schmieg, N., Menendez, G., Schiavo, G., Terenzio, M., 2014. Signalling endosomes in axonal transport: travel updates on the molecular highway. Semin. Cell Dev. Biol. 27, 32-43.

Schmitt, A., Dreyer, F., John, C., 1981. At least three sequential steps are involved in the tetanus toxin-induced block of neuromuscular transmission. Naunyn Schmiedebergs Arch. Pharmacol. 317, 326-330.

Simpson, L.L., 2000. Identification of the characteristics that underlie botulinum toxin potency: implications for designing novel drugs. Biochimie 82, 943-953.

Sleigh, J.N., et al., 2017a. Trk receptor signaling and sensory neuron fate are perturbed in human neuropathy caused by Gars mutations. Proc. Natl. Acad. Sci. U. S. A. 114, E3324E3333.

Sleigh, J.N., Vagnoni, A., Twelvetrees, A.E., Schiavo, G., 2017b. Methodological advances in imaging intravital axonal transport. F1000Res 6, 200.

Stevens, R.C., Evenson, M.L., Tepp, W., DasGupta, B.R., 1991. Crystallization and preliminary X-ray analysis of botulinum neurotoxin type A. J. Mol. Biol. 222, 877-880. 
Stoeckel, K., Schwab, M., Thoenen, H., 1977. Role of gangliosides in the uptake and retrograde axonal transport of cholera and tetanus toxin as compared to nerve growth factor and wheat germ agglutinin. Brain Res. 132, 273-285.

871 Sugawara, Y., Yutani, M., Amatsu, S., Matsumura, T., Fujinaga, Y., 2014. Functional 872 Dissection of the Clostridium botulinum Type B Hemagglutinin Complex: Identification of the 873 Carbohydrate and E-Cadherin Binding Sites. PLoS One 9, e111170.

874 Swaminathan, S., Eswaramoorthy, S., 2000. Structural analysis of the catalytic and binding 875 sites of Clostridium botulinum neurotoxin B. Nat. Struct. Biol. 7, 693-699.

Takamizawa, K., Iwamori, M., Kozaki, S., Sakaguchi, G., Tanaka, R., Takayama, H., Nagai, Y., 1986. TLC immunostaining characterization of Clostridium botulinum type A neurotoxin binding to gangliosides and free fatty acids. FEBS Lett. 201, 229-232.

Terenzio, M., Golding, M., Russell, M.R., Wicher, K.B., Rosewell, I., Spencer-Dene, B., IshHorowicz, D., Schiavo, G., 2014a. Bicaudal-D1 regulates the intracellular sorting and 881 signalling of neurotrophin receptors. EMBO J. 33, 1582-1598.

Terenzio, M., Golding, M., Schiavo, G., 2014b. siRNA screen of ES cell-derived motor neurons identifies novel regulators of tetanus toxin and neurotrophin receptor trafficking. 884 Front. Cell. Neurosci. 8, 140.

885 886

Toivonen, J.M., Olivan, S., Osta, R., 2010. Tetanus toxin C-fragment: the courier and the cure? Toxins (Basel) 2, 2622-2644.

Tsukamoto, K., Kohda, T., Mukamoto, M., Takeuchi, K., Ihara, H., Saito, M., Kozaki, S., 2005. Binding of Clostridium botulinum type $C$ and D neurotoxins to ganglioside and phospholipid. Novel insights into the receptor for clostridial neurotoxins. J. Biol. Chem. 280, 35164-35171.

Udwadia, F.E., 1994. Tetanus. Oxford University Press, Bombay.

Vale, R.D., 2003. The molecular motor toolbox for intracellular transport. Cell 112, 467-480.

van Ermengem, E., 1979. Classics in infectious diseases. A new anaerobic bacillus and its relation to botulism. E. van Ermengem. Originally published as "Ueber einen neuen anaeroben Bacillus und seine Beziehungen zum Botulismus" in Zeitschrift fur Hygiene und Infektionskrankheiten 26: 1-56, 1897. Rev. Infect. Dis. 1, 701-719.

Wade, A., Thomas, C., Kalmar, B., Terenzio, M., Garin, J., Greensmith, L., Schiavo, G., 2012. Activated leukocyte cell adhesion molecule modulates neurotrophin signaling. J. Neurochem. 121, 575-586.

Wang, T., et al., 2016. Flux of signalling endosomes undergoing axonal retrograde transport is encoded by presynaptic activity and TrkB. Nat Commun 7, 12976.

Wang, T., et al., 2015. Control of autophagosome axonal retrograde flux by presynaptic activity unveiled using botulinum neurotoxin type a. J. Neurosci. 35, 6179-6194. 
904 Weisemann, J., Stern, D., Mahrhold, S., Dorner, B.G., Rummel, A., 2016. Botulinum 905 neurotoxin serotype a recognizes its protein receptor SV2 by a different mechanism than 906 botulinum neurotoxin B synaptotagmin. Toxins (Basel) 8.

907 Wiegand, H., Erdmann, G., Wellhoner, H.H., 1976. 125l-labelled botulinum A neurotoxin: 908 pharmacokinetics in cats after intramuscular injection. Naunyn Schmiedebergs Arch. 909 Pharmacol. 292, 161-165.

910 Williamson, L.C., Bateman, K.E., Clifford, J.C., Neale, E.A., 1999. Neuronal sensitivity to 911 tetanus toxin requires gangliosides. J. Biol. Chem. 274, 25173-25180.

912 Yao, G., Lee, K., Gu, S., Lam, K.H., Jin, R., 2014. Botulinum neurotoxin A complex 913 recognizes host carbohydrates through its hemagglutinin component. Toxins (Basel) 6, 624914635.

915 Yeh, F.L., Dong, M., Yao, J., Tepp, W.H., Lin, G.Y., Johnson, E.A., Chapman, E.R., 2010. 916 SV2 Mediates Entry of Tetanus Neurotoxin into Central Neurons. PLoS Pathog. 6, 917 e1001207.

918 Zanetti, G., Azarnia Tehran, D., Pirazzini, M., Binz, T., Shone, C.C., Fillo, S., Lista, F., 919 Rossetto, O., Montecucco, C., 2015. Inhibition of botulinum neurotoxins interchain disulfide 920 bond reduction prevents the peripheral neuroparalysis of botulism. Biochem. Pharmacol. 98, $921522-530$.

922 Zhang, S., et al., 2017. Identification and characterization of a novel botulinum neurotoxin. 923 Nat Commun 8, 14130.

924 Zhang, Y., Varnum, S.M., 2012. The receptor binding domain of botulinum neurotoxin 925 serotype $\mathrm{C}$ binds phosphoinositides. Biochimie 94, 920-923. 
928 Figure 1. Trafficking of the tetanus (TeNT) and botulinum neurotoxins (BoNT) in vivo

929 (adapted from Schmeig et al., 2014b). A. Anatomical connections between skeletal 930 muscles, spinal cord motor neurons and their afferent cells. Motor neurons innervate 931 skeletal muscles via the neuromuscular junction (NMJ). The motor neuron axon is 932 myelinated and can reach over a meter in length in humans. The motor neuron soma is 933 located in the spinal cord, where it forms contacts with adjacent interneurons and upper 934 motor neurons. B. Internalisation at the NMJ. Both TeNT (T; in blue) and BoNTs (B; in 935 green) accumulate in the synaptic space of the NMJ, which is filled with basal lamina (in 936 yellow). TeNT binds to polysialogangliosides and nidogens, and this complex is targeted to 937 the axonal retrograde transport route (solid blue arrow). At higher doses or with the 938 unavailability of nidogens, TeNT is able to bind SV2 and can enter synaptic vesicle (SV) 939 recycling at the NMJ (thinner blue arrow) (Bercsenyi et al., 2014). The majority of BoNT 940 molecules remain at the NMJ (solid green arrow), where they cleave synaptic SNAREs, 941 thereby blocking the fusion of (SVs) containing acetylcholine and causing flaccid paralysis. 942 However, a fraction of BoNT/A may enter organelles targeted to the soma (thinner green 943 arrow), such as axonal signalling endosomes (Restani et al., 2012a) or autophagosomes 944 (Wang et al., 2015). C. Axonal retrograde transport. TeNT is transported to the soma via 945 axonal signalling endosomes, along with neurotrophins and their receptors. This long-range 946 retrograde axonal transport, which also requires the GTP-bound form of the small GTPase 947 Rab7 (in purple) (Deinhardt et al., 2006b), is dependent on the microtubule-based motor, 948 cytoplasmic dynein (in red). D. Interneuronal transfer of TeNT into inhibitory 949 interneurons. Once in the motor neuron soma in the spinal cord (Bilsland et al., 2010), 950 TeNT is released into the extracellular medium and is internalised by SV recycling into 951 inhibitory interneurons, where it cleaves VAMP/synaptobrevin, thereby blocking inhibitory 952 neurotransmission. This impairs the balance between inhibitory and excitatory afferents on 953 the motor neurons, leading to disruptions in co-ordinated muscle contraction and spastic 954 paralysis. 
Figure 1

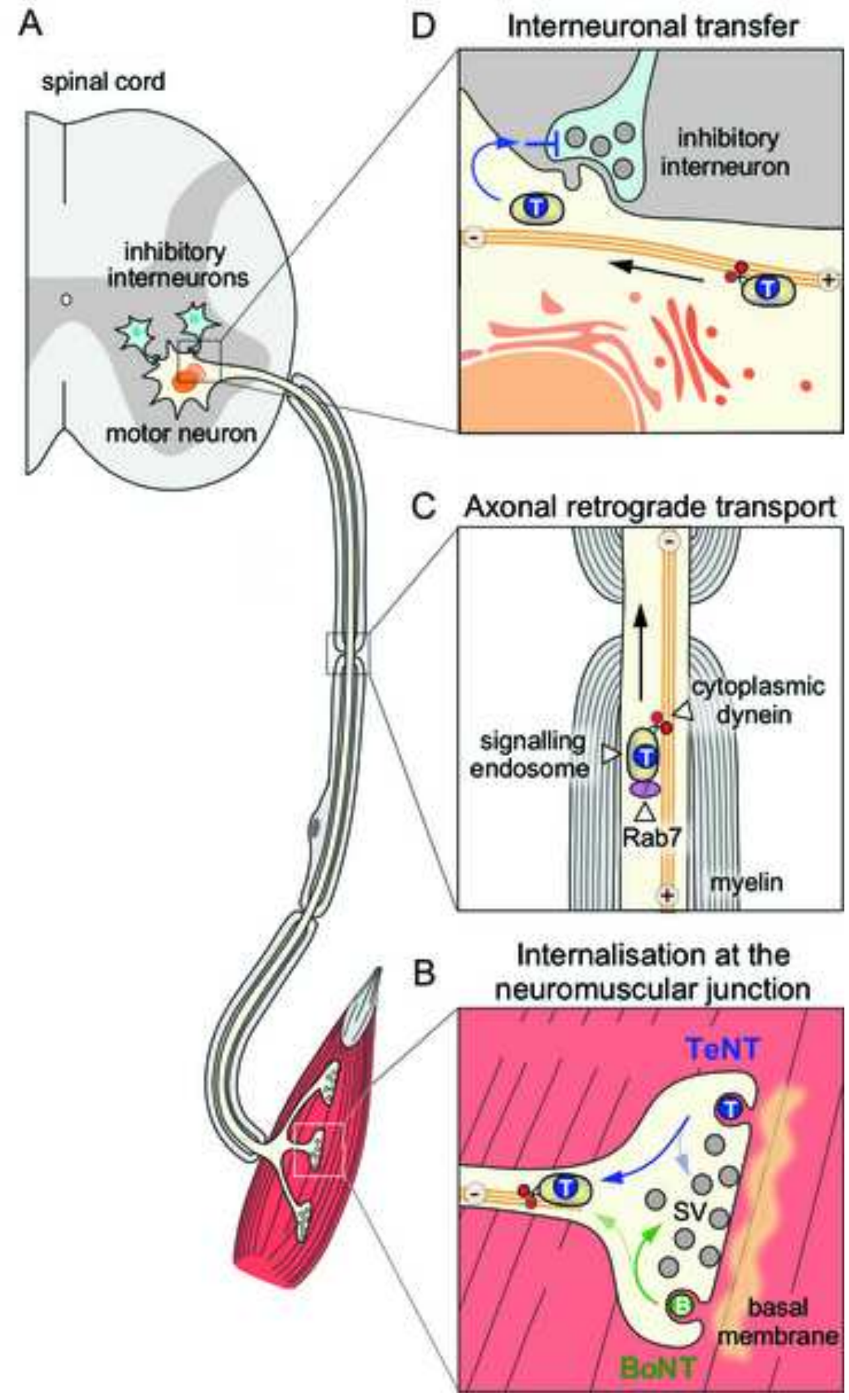

